\title{
Quantitative Assessment of Angiogenesis in Murine Antigen-Induced Arthritis by Intravital Fluorescence Microscopy
}

\author{
M. Schmitt-Sody ${ }^{a}$ J. Landes ${ }^{b} \quad$ S.P. Zysk ${ }^{a}$ C. Pellengahr ${ }^{a} \quad$ F. Krombach ${ }^{b}$ \\ H.J. Refior ${ }^{a}$ K. Messmer ${ }^{b}$ A. Veihelmann ${ }^{a}, b$ \\ a Department of Orthopedics and bInstitute for Surgical Research, Ludwig Maximilians University of Munich, \\ Munich, Germany
}

\section{Key Words}

Angiogenesis · Arthritis · Mouse · Microscopy, intravital

\begin{abstract}
Inhibition of angiogenesis might be a therapeutic approach to prevent joint destruction caused by the overgrowing synovial tissue during chronic joint inflammation. The aim of this study was to investigate angiogenesis in the knee joint of mice with antigen-induced arthritis (AIA) by means of intravital microscopy. In 14 mice (C57BL6/129Sv) intravital microscopic assessment was performed on day 8 after AIA induction in two groups (controls, AIA). Synovial tissue was investigated by intravital fluorescence microscopy using FITC-dextran (150 kD). Quantitative assessment of vessel density was performed according to the following categories: functional capillary density (FCD, vessels $<10 \mu \mathrm{m}$ in diameter), functional vessel density (FVD, vessels $>10 \mu \mathrm{m}$ ) and FVD of vessels with angiogenic criteria (convoluted vessels, abrupt changes of diameter, vessels which are generated by sprouting and progressively pruned and remodelled). Microvessel count was performed using immunohistochemistry. There was no significant difference in FCD between the control group $\left(337 \pm 9 \mathrm{~cm} / \mathrm{cm}^{2}\right.$; mean \pm SEM) and the AIA group (359 $\left.\pm 13 \mathrm{~cm} / \mathrm{cm}^{2}\right)$. The density of vessels larger than $10 \mu \mathrm{m}$ diameter was sig-
\end{abstract}

nificantly increased in animals with AIA (135 \pm 10 vs. 61 $\pm 5 \mathrm{~cm} / \mathrm{cm}^{2}$ in control). The density of blood vessels with angiogenic criteria was enhanced in arthritic animals (79 \pm 17 vs. $12 \pm 2 \mathrm{~cm} / \mathrm{cm}^{2}$ in control). There was a significant increase in the microvessel count in arthritic animals (297 \pm 25 vs. $133 \pm 16 \mathrm{~mm}^{-2}$ in control). These findings demonstrate that angiogenesis in murine AIA can be assessed quantitatively using intravital microscopy. Further studies will address antiangiogenic strategies in AIA.

Copyright $($ C 2003 S. Karger AG, Base

\section{Introduction}

Rheumatoid arthritis (RA) is a chronic progressive disease involving both local and systemic inflammation that causes joint destruction, deformity, disability and premature death [1]. In RA, the vascular endothelium is among the key targets of circulating mediators of inflammation and controls the trafficking of cells and molecules from the bloodstream toward the synovial tissue. Local blood vessel proliferation allows the pannus to develop and grow, thereby promoting cartilage and adjacent bone destruction and joint remodeling, leading to severe pain and impairment of mobility [2,3]. These changes are accompanied by alterations in the synovial microcircula-

\section{KARGER \\ Fax +4161306 1234 \\ E-Mail karger@karger.ch \\ www.karger.com

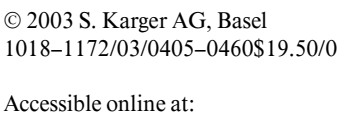

Dr. Andreas Veihelmann

Department of Orthopedics, Klinikum Grosshadern, Ludwig Maximilians University Marchioninistrasse 15, DE-81377 Munich (Germany)

Tel. +49 897095 2613, Fax +49 8970955614

E-Mail andreas.veihelmann@helios.med.uni-muenchen.de 
tion [4]. RA synovitis involves local activation of lymphocytes, inflammation, and synovial hyperplasia as well as angiogenesis [1].

Angiogenesis, the process by which new blood vessels are formed by outgrowth from existing ones, plays an important role in active proliferation of inflammatory synovial tissue, which is a principal pathophysiological feature in RA. The RA synovial tissue is rich in new vessels. Enhanced angiogenic activity perpetuates leukocyte extravasation and thus the progression of RA [5]. It has, therefore, been suggested that the inhibition of blood supply, resulting in a suppression of pannus growth, could be a beneficial element of antiarthritic therapy [6].

Because RA is an angiogenic disease [7], recent research efforts have focused on the inhibition of angiogenesis. In a rat model of arthritis, the antiproliferative agent TNP 470 was found to suppress established disease, in parallel with marked inhibition of pannus formation and neovascularization [8-10]. More recently specific antagonists of $\alpha \mathrm{V} \beta 3$ were used in a rabbit model resembling human RA. Intra-articular injections of $\alpha \mathrm{V} \beta 3$ antibody decreased vascularity in the arthritic synovium, which was associated with a significant decrease of all arthritis parameters including joint swelling and synovitis [11].

Most of the investigations regarding antiangiogenic strategies and their effects on the rheumatoid synovial microcirculation have relied on clinical and histological parameters. It is still unclear whether the density of blood vessels in the arthritic synovium per unit area is increased, unchanged or even gets reduced $[12,13]$. The lack of a suitable animal model has restricted previous efforts primarily to histological studies. In our recently published study intravital microscopy has been successfully used to quantify the leukocyte-endothelial cell interaction in mouse antigen-induced arthritis (AIA) [14]. Yet, no studies have been reported which directly demonstrate the in vivo effects of antiangiogenic therapy on the synovial microcirculation. Therefore, it was our aim to investigate angiogenesis and to develop a quantitative technique for assessing angiogenesis in the knee joint of mice with AIA in vivo, with the use of our recently developed model for intravital microscopic analysis of the mouse synovial microvasculature [15].

\section{Materials and Methods}

\section{Animals}

Female inbred Balb/c mice (C57BL6/129Sv, Charles River, Sulzfeld, Germany) at 8-10 weeks of age, weighing 18-21 g were used for the experiments. The animals were kept in an air-conditioned envi- ronment with 12-hour light/dark cycles, housed in single cages and fed laboratory chow (Ssniff, Spezialdiäten, Soest, Germany) and water ad libitum. Before starting the experiments, they were randomly assigned to the control or AIA group.

\section{Antigen-Induced Arthritis}

On days -21 and -14 prior to the induction of arthritis mice were immunized by a subcutaneous injection of $100 \mu \mathrm{g}$ of methylated bovine serum albumin (mBSA; Sigma, Deisenhofen, Germany), dissolved in $50 \mu 1$ of Freund's complete adjuvant (Sigma) and supplemented with $2 \mathrm{mg} / \mathrm{ml}$ heat-killed Myobacterium tuberculosis strain H37RA (Difco, Augsburg, Germany) and an additional intraperitoneal injection of $2 \times 10^{9}$ heat-killed Bordetella pertussis (Institute of Microbiology, Berlin, Germany) as previously described by Brackertz et al. [16]. Finally, arthritis was induced on day 0 by injection of $100 \mu \mathrm{g}$ mBSA in $50 \mu \mathrm{l}$ saline into the left knee joint using a sterile 33 -gauge microcannula. Control animals underwent the same procedure but received only equivalent volumes of saline.

\section{Experimental Groups}

Animals were randomly assigned to two groups: a healthy control group $(n=7)$ and a group with AIA $(n=7)$. To assess the severity of AIA, joint swelling was determined daily until day 8 by measuring the transverse diameter of the knee joint using a caliper in units of $0.1 \mathrm{~mm}$. Intravital microscopy as well as tissue sampling were performed on day 8 after AIA in both groups.

\section{Surgical Preparation}

Mice were anesthetized by inhalation of isoflurane $1.5 \%$ (Forence, Abbott, Wiesbaden, Germany) and a mixture of $\mathrm{O}_{2} / \mathrm{N}_{2} \mathrm{O}$, using a vaporizer (Dräger, Lübeck, Germany). Arterial and venous catheters were implanted into the tail. The mean arterial blood pressure was measured using the arterial catheter. Animals were kept on a heating pad to stabilize body temperature. The left hind limb was placed on a stage with the knee slightly flexed. Through a $1-\mathrm{cm}$ incision distal to the patellar tendon, the tendon was carefully mobilized, cut transversally, and elevated to provide visual access to the intra-articular synovial tissue as described elsewhere [15]. At the end of the experiment, the animals were sacrificed with an intravenous injection of $10 \mathrm{mg}$ pentobarbital (Nembutal, Sanofi, Hannover, Germany). The knee joints were then removed for immunohistochemistry. The experiments were approved and performed according to the German legislation for the protection of animals.

\section{Intravital Fluorescence Microscopy}

The microscopic setup has previously been described in detail [17]. An intravital microscope (Zeiss, Oberkochen, Germany) equipped with a 20 -fold water immersion objective (total magnification 432-fold: Zeiss, Jena, Germany) was used to visualize the synovial microcirculation. Three regions of interest were selected, each containing postcapillary venules (18-40 $\mu \mathrm{m}$ in diameter) or arterioles (8-14 $\mu \mathrm{m}$ in diameter), as well as capillaries for the measurement of functional capillary density (FCD). By means of a computer-controlled platform which moves step by step driven by the computer, identical vessel segments were reinvestigated with respect to the parameters described above. For visualization of plasma, a variable 12-volt, 100-watt halogen light source and the Zeiss filter set 09 [band pass (BP) 450-490, dichroic filter (FT) 510, long pass (LP) 520; Zeiss] were used in conjunction with a bolus injection of fluorescein isothiocyanate (FITC)-dextran (molecular mass $150 \mathrm{kD}, 15 \mathrm{mg} / \mathrm{kg}$ 
Fig. 1. Course of changes in knee joint diameter following arthritis induction (time point indicated by the dotted line). Bars show the mean \pm SEM of 7 animals per group. $* \mathrm{p}<$ 0.05 vs. control group.

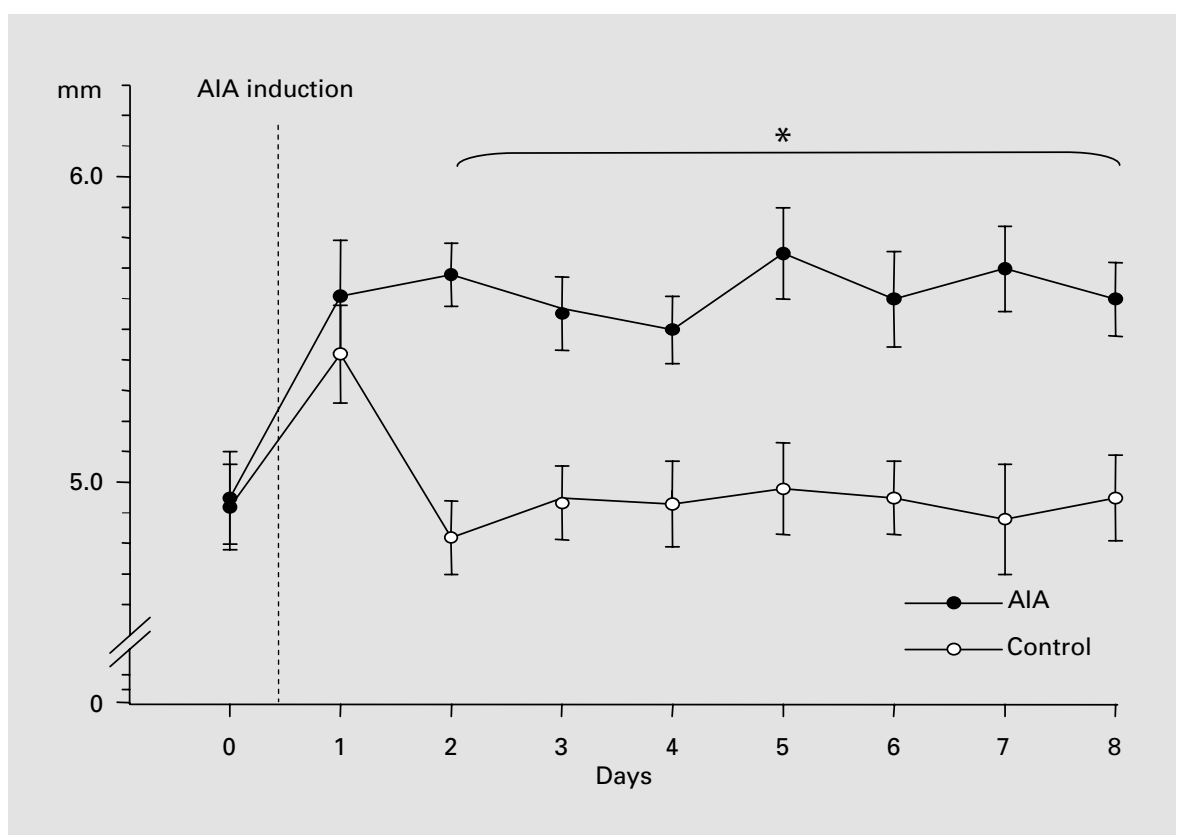

body weight intravenously; Sigma). Microscopic images were acquired and recorded on videotape. Data analysis was performed offline using a computer-assisted analysis system (CAP-Image, Dr. Zeintl, Heidelberg, Germany) [18].

\section{Microcirculatory Parameters}

The following microcirculatory parameters were assessed using intravital microscopy: diameters of arterioles and venules, FCD (vessels $<10 \mu \mathrm{m}$ in diameter), functional vessel density (FVD; vessels $>10 \mu \mathrm{m}$ in diameter) and the functional density of vessels exhibiting angiogenic criteria (at least one of the following: convoluted vessel, abrupt changes of diameter, vessels which are generated by sprouting and progressively pruned and remodelled as described by Risau [19]), defined as the length of red blood cell-perfused capillaries or vessels within the observation area (expressed as $\mathrm{cm} / \mathrm{cm}^{2}$ ).

\section{Immunhistochemistry/Histological Score}

Staining for vascular endothelial cells was performed on cryopreserved tissue sections using the avidin-biotin immunoperoxidase complex technique. Six-micrometer-thick sections, mounted on glass slides, were deparaffinized with xylene. Endogenous peroxidase was blocked by incubation with $2 \%$ hydrogen peroxide for $10 \mathrm{~min}$. The tissue sections were incubated for $1 \mathrm{~h}$ with the factor VIII-related antigen/von Willebrand factor (vWF) monoclonal antibody (clone F8/86, Dako, Glostrup, Denmark) at a 1 to 50 dilution. The revelation of the staining was performed using the Vectastain Elite $\mathrm{ABC}$ peroxidase mouse IgG kit (Vector, Burlingame, Calif., USA) and the diaminobenzidine (Dako, Glostrup, Denmark) as chromogen. Peroxidase-conjugated avidin was used at a dilution of 1:500. The sections were finally counterstained with hematoxylin.

Microvessel density was determined according to the technique of Weidner et al. [20] by using an ocular eyepiece screen and an examination area of $0.25 \mathrm{~mm}^{2}$ at a total magnification of 200 .
To analyze the extent and to evaluate the severity of the arthritis, histological sections were performed using a standard scoring protocol introduced by Brackertz et al. [16].

\section{Statistical Analysis}

The data are expressed as mean \pm SEM. Statistical significance was tested using a repeated measurements ANOVA on ranks (Friedman's test) and Dunn's follow-up testing. $\mathrm{p}$ values $<0.05$ were considered significant.

\section{Results}

\section{Knee Joint Diameter}

Figure 1 shows the time course of changes in knee joint diameter in both groups over the observation time of 8 days after arthritis induction. In the control group there was an increase in joint diameter on day 1 , which was most probably due to the injected volume. However, the joint diameter returned to baseline values starting on day 2 in control mice. In contrast, significant swelling of the knee joint was observed from day 2 until day 8 in mice with AIA compared with the measurements in control joints.

No significant change of the mean arterial blood pressure occurred during the entire course of the experiment in the two groups. The arthritic group demonstrated no sign of a lack of care of their coat or any unusual behavior. There was no significant loss of body weight in the AIA group in comparison to the control group. 
Fig. 2. Capillaries, arterioles and venules in the mouse synovial fat tissue visualized by intravital fluorescence microscopy (plasma stained with FITC-dextran). $\times$ 432. A Vessels of the control group. B High-density capillary network and vessels with angiogenic criteria of mice with AIA.

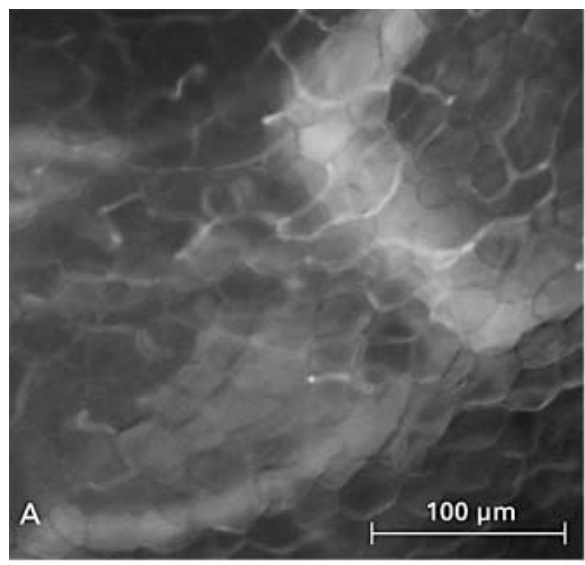

Control

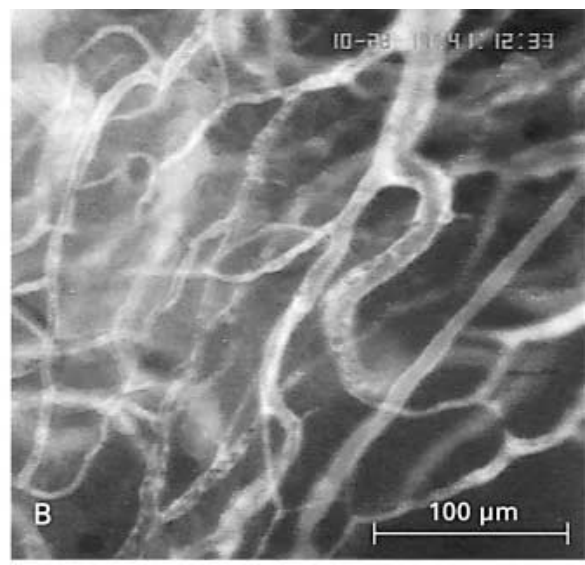

AIA

\section{Microcirculatory Parameters}

Typical FITC intravital microscopic images in a control mouse and in a mouse with AIA are shown in figure 2. The tissue in the AIA mice presents a high-density capillary network and arterioles and postcapillary venules with angiogenic criteria. As shown in figure 3 there was no significant difference in FCD between the control group $\left(337 \pm 9 \mathrm{~cm} / \mathrm{cm}^{2}\right.$; mean \pm SEM) and the AIA group $\left(359 \pm 13 \mathrm{~cm} / \mathrm{cm}^{2}\right)$. However AIA induction resulted in a significant increase in the density of vessels $>10 \mu \mathrm{m}$ diameter $\left(135 \pm 10 \mathrm{~cm} / \mathrm{cm}^{2}\right)$ at day 8 compared to the control group (61 $\left.\pm 5 \mathrm{~cm} / \mathrm{cm}^{2}\right)$. Furthermore, the density of blood vessels with angiogenic criteria was significantly enhanced in arthritic animals on day 8 after AIA induction $\left(79 \pm 17 \mathrm{~cm} / \mathrm{cm}^{2}\right)$ in comparison to the control mice $\left(12 \pm 2 \mathrm{~cm} / \mathrm{cm}^{2}\right)$.

\section{Immunohistochemistry/Histological Score}

Immunohistochemistry revealed a strong expression of vWF on the endothelium of synovial microvessels, as shown in figure 4, mainly in the tissue sections of animals with AIA, while it was only weak in the sections of control animals. The results of the immunohistochemistry are shown in figure 5 . There was a significant increase in the microvessel count in arthritic animals $\left(297 \pm 25 / \mathrm{mm}^{-2}\right)$ in contrast to the control group $\left(133 \pm 16 / \mathrm{mm}^{-2}\right)$.

On day 8 after induction of arthritis, the histological score revealed two or more synovial lining cells and perivascular infiltration of leukocytes as well as hyperplasia of synovium and pannus formation indicating that arthritis has been induced in comparison to the control group as shown in table 1.

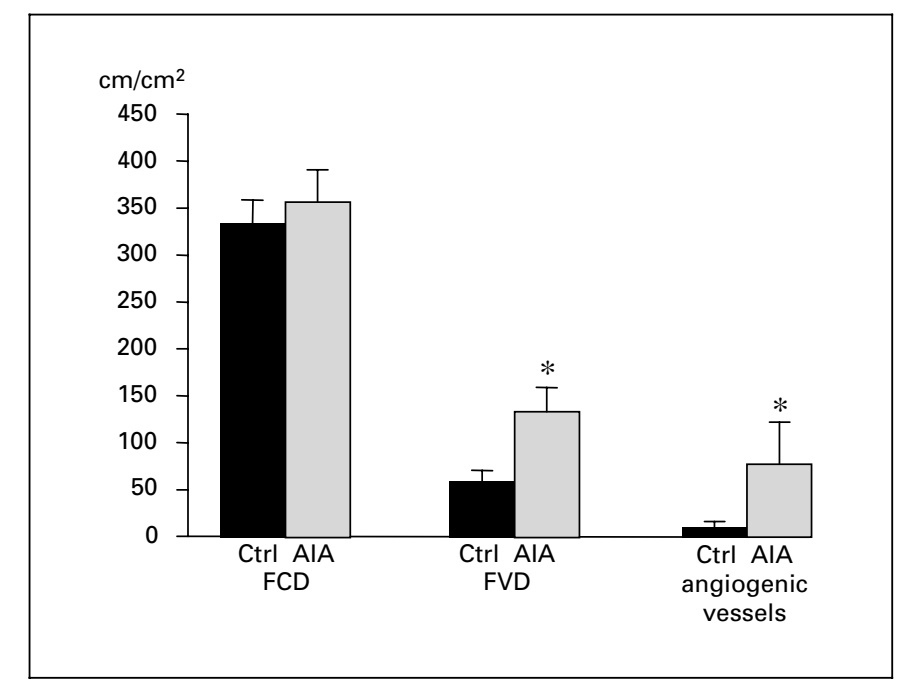

Fig. 3. FCD (vessels $<10 \mu \mathrm{m}$ ), FVD (vessels $>10 \mu \mathrm{m}$ ) and density of vessels with angiogenic criteria are shown. ${ }^{*} \mathrm{p}<0.05$ vs. control group (ctrl). Data are given as mean $\pm \operatorname{SEM}(n=7)$.

\section{Discussion}

One of the earliest features of rheumatoid synovitis is the development of a new vascular network, which serves to promote the delivery of cells and nutrients to the invading pannus [21]. Histological studies in patients with early RA, who had clinical and histological evidence of knee synovitis, have shown a significant increase in both vascular proliferation and the number of blood vessels per square millimeter as compared with postmortem control samples [22]. Several studies have suggested beneficial effects of antiangiogenic therapy in RA. Antibodies to 
Fig. 4. Expression of vWF on synovial endothelium. A Tissue sections of control animals. B Tissue sections of animals with AIA.
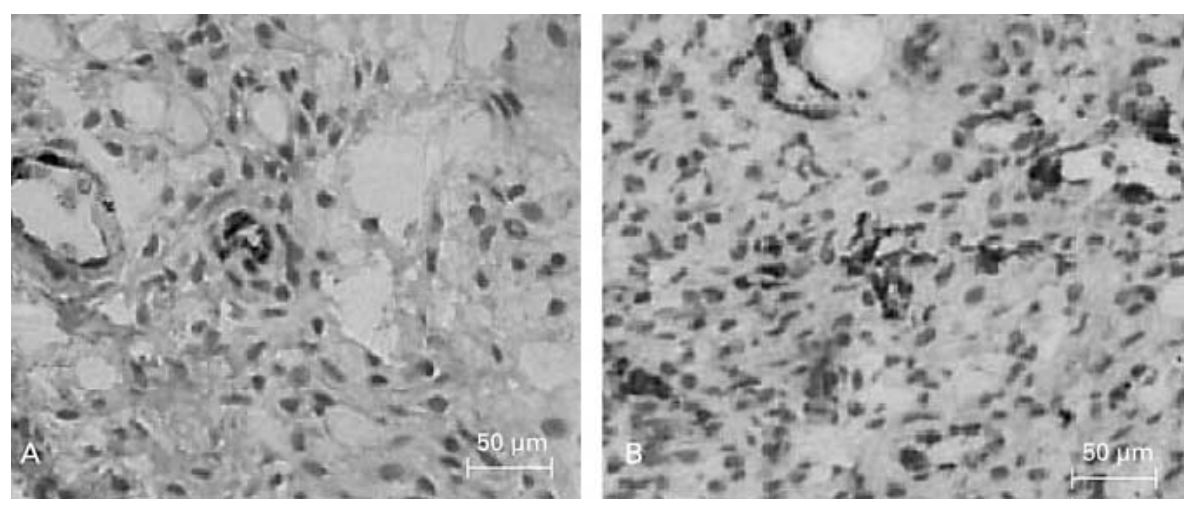

Table 1. Histological score of all individual animals

\begin{tabular}{|c|c|c|c|c|c|}
\hline \multirow[t]{2}{*}{ Groups } & \multicolumn{5}{|c|}{ Histological score } \\
\hline & 0 & 1 & 2 & 3 & 4 \\
\hline Control $(\mathrm{n}=7)$ & 7 & 0 & 0 & 0 & 0 \\
\hline $\operatorname{AIA}(\mathrm{n}=7)$ & 0 & 0 & 3 & 3 & 1 \\
\hline
\end{tabular}

AIA: histological sections graded as $0=$ normal knee joint; $1=$ normal synovium with occasional mononuclear cells; 2 = two and more synovial lining cells and perivascular infiltrates of leukocytes; 3 = hyperplasia of synovium and dense infiltration; 4 = synovitis and pannus formation and cartilage/subchondral bone erosions [16].

VEGF have been found to partially neutralize the proliferative activity of endothelial cells in RA tissue explant cultures [23]. In the rat model of collagen-induced arthritis, angiogenesis inhibitors prevented the onset of collagen-induced arthritis and suppressed established disease $[8,10]$ in the presence of reduced serum concentrations of VEGF [9]. Anti-Flt 1 treatment significantly reduced the clinical signs of arthritis and revealed a 3-fold reduction in a histological score of the degree of synovial hyperplasia, inflammation and pannus formation in a mouse model of collagen-induced arthritis [24]. Treatment of human RA with monoclonal antibody to $\mathrm{TNF} \alpha$ significantly reduced serum VEGF in a time- and dose-dependent manner and correlated with alterations of disease parameters, such as C-reactive protein (CRP) levels and swollen joint score [25]. The effects of established antirheumatic drugs, gold salts, $D$-penicillamine, methotrexate are known to be partly mediated by inhibition of endothelial cell proliferation [26, 27]. Monitoring response to treatment rests on histological and clinical parameters such as

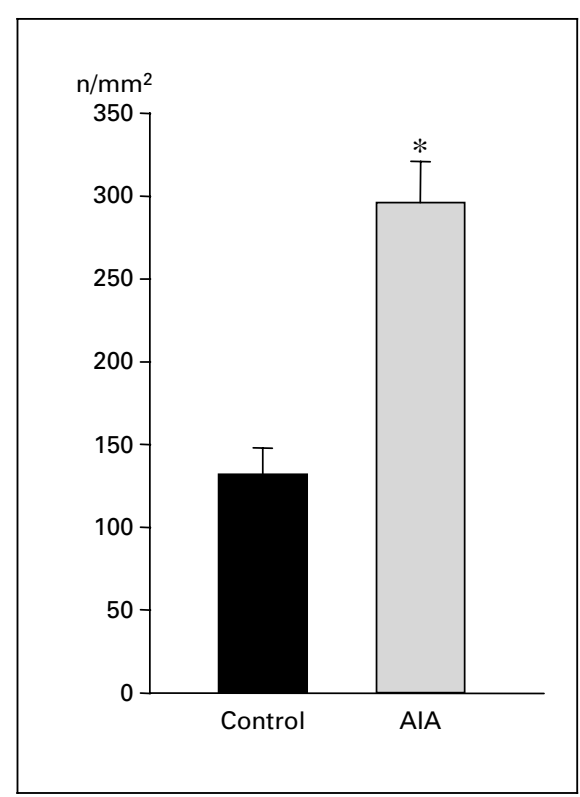

Fig. 5. Microvessel count. $* p<0.05$ vs. control group. Data are given as mean \pm SEM.

joint swelling or systemic markers of joint inflammation, such as CRP. Even effective control of inflammation does not necessarily prevent deterioration of joint damage in RA. Therefore, a better disease monitoring is essential if better antiangiogenic strategies are to be developed.

The current study has shown for the first time in an animal model of arthritis in vivo that there is an increase of FVD at the site of inflammation. This was associated with an increase of the density of vessels with angiogenic criteria. Thus, there are significant changes occurring in the synovial microcirculation of the knee joint during AIA 
which demonstrate that angiogenesis can be assessed quantitatively using intravital microscopy.

AIA is an established animal model for the study of human RA [16]. The main advantage of AIA in comparison to other established animal models is that arthritis is induced in the knee joint which lends itself for microscopic observations. The knee joint is the only joint which can be accessed for intravital microscopy without inducing major trauma [15]. In this study, arthritis was actually induced in the knee, as shown by presence of swelling over the entire observation period and the high histological score on day 8 in all animals with AIA. Thus, the microvascular changes in this study are due to AIA and are not an artifact resulting from the surgical preparation [15].

The efficiency of exchange between the synovial capillaries and the joint cavity is dependent upon the number of vessels and blood flow as well as endothelial permeability. In the present work, angiogenesis, characterized by FCD (vessels $<10 \mu \mathrm{m}$ in diameter), FVD (vessels $>10 \mu \mathrm{m}$ in diameter) and the functional density of vessels exhibiting angiogenic criteria (convoluted vessels, abrupt changes of diameter, vessels which are generated by sprouting and progressively pruned and remodelled), in the synovium was for the first time studied quantitatively using intravital microscopy. The results of this study show no significant difference in FCD between the control group and the AIA group. However, the FVD was significantly increased in animals with AIA. Furthermore, the density of vessels exhibiting angiogenic criteria was significantly enhanced in arthritic animals. The term vessel density indicates that only red blood cell-perfused vessels are measured, this means blood vessels which are involved in the oxygenation and nutrition of the tissue. Previous studies have relied on histology and could only determine the anatomical vessel density in the synovium without any knowledge of whether the vessels counted were actually perfused or not $[12,13,28]$.

There was no increase in the number of perfused capillaries (FCD) in arthritic animals in our study. This is likely the result of the elevated joint pressure associated with RA, because a large number of nonperfused capillaries $(<10 \mu \mathrm{m})$ were present in animals with AIA. The edema formation which accompanies the influx of leukocytes into the joint could result in a compression of the small capillaries similar to that seen following ischemia-reperfusion injury [29]. The compression of the capillaries leads to a reduction of diameter and thus to a higher resistance to flow, which can result in impaired nutritional blood flow.

Our results of an enhancement of FVD and of the density of blood vessels with angiogenic criteria are in agree- ment with previous histological studies and are most likely the result of angiogenesis which is known to occur in chronic inflammation $[11,30]$. Pannus formation in RA involves proliferation, migration, and recruitment of inflammatory cells, which is associated with an increased production of TNFa, IL-1, and nitric oxide; the latter have been shown to exert both indirect and direct angiogenic activities [30]. Furthermore, it has previously been demonstrated that the expression of E-selectin,VCAM-1, and $\alpha \mathrm{V} \beta 3$, which is detected in early RA synovial tissue [31], is associated with angiogenesis [11, 32]. Thus, angiogenesis is the major mechanism responsible for the significant increase in FVD and density of vessels with angiogenic criteria seen in animals with AIA.

In addition, there was a significant increase in the microvessel count in arthritic animals. These results of the immunohistochemical analysis confirm the observations made by means of intravital microscopy.

However, immunohistochemical methods for the detection of vWF and the CD34 antigen on microvessels in tumor tissue is hampered by costaining of a proportion of the lymphatic vessels. Although neoplasms are assumed not to elicit the formation of a new lymphatic drainage system [33], the inclusion of preexisting lymphatic vessels may lead to false-positive microvessel counts if their antigens are also highlighted. By intravital microscopy after intravenous injection of FITC-dextran lymphatic vessels could not be detected. Lymphatics can only be stained by local injection into the footpad of mice [34]. Therefore, it is astonishing that in contrast to control animals we only observed a nearly doubled number of the microvessel count in arthritic mice whereas the density of angiogenic vessels assessed by intravital microscopy was increased more than 6 times compared to that of the control group.

In summary, in this study the in vivo changes of angiogenesis in an animal model of arthritis have been quantitatively assessed. This work describes for the first time a quantitative intravital microscopic measure of vascular density in arthritis disease, which seems to be more sensitive in the registration of newly formed blood vessels than microvessel count by vWF. Quantifying the rate of angiogenic enhancement may prove to be a useful technique for evaluating drugs that influence angiogenesis.

\section{Acknowledgments}

We gratefully acknowledge the excellent technical assistance of Mrs. S. Muenzing in the immunohistochemical analyses.

J Vasc Res 2003;40:460-466 465 


\section{References}

1 Harris ED Jr: Etiology and pathogenesis of rheumatoid arthritis; in Kelly WN, Harris ED Jr, Ruddy S, Sledge CB (eds): Textbook of Rheumatology. Philadelphia, Saunders, 1993 , pp 833-873.

2 Sewell KL, Trendham DE: Pathogenesis of rheumatoid arthritis. Lancet 1993;341:283286.

3 Feldmann M, Brennan FM, Maini RN: Rheumatoid arthritis. Cell 1996;85:307-310.

4 Gearing AJH, Newman W: Circulating adhesion molecules in disease. Immunol Today 1993;14:506-512.

5 Harris ED Jr: Rheumatoid arthritis: Pathophysiology and implication for therapy. N Engl J Med 1990;332:1277-1287.

6 Battegay EJ: Angiogenesis: Mechanistic insights, neovascular diseases, and therapeutic prospects. J Mol Med 1995;73:333-346.

7 Folkman J: Angiogenesis in cancer, vascular, rheumatoid and other disease. Nat Med 1995; $1: 27-31$.

8 Oliver SJ, Banquerigo ML, Brahn E: Suppression of collagen-induced arthritis using an angiogenesis inhibitor, AGM-1470, and a microtuble stabilizer, taxol. Cell Immunol 1994;157. 291-299.

9 Oliver SJ, Cheng TP, Banquerigo ML, Brahn E: Suppression of collagen-induced arthritis using an angiogenesis inhibitor, AGM-1470, in combination with cyclosporin: Reduction of vascular endothelial growth factor (VEGF). Cell Immunol 1996;166:196-206.

10 Peacock DJ, Banquerigo ML, Brahn E: Angiogenesis inhibition suppresses collagen arthritis. J Exp Med 1992;175:1135-1138.

11 Stogard CM, Stupack DG, Joncyk A, Goodman SL, Fox RI, Cheresh DA: Decreased angiogenesis and arthritic disease in rabbits treated with an alphavbeta3 antagonist. J Clin Invest 1999; 103:47-54.

12 Stevens CR, Blake DR, Merry P, Revell PA, Levick JR: A comparative study by morphometry of the microvasculature in normal and rheumatoid synovium. Arthritis Rheum 1991; 34:1508-1513.

13 Fitzgerald O, Bresnihan B: Synovial vascularity is increased in rheumatoid arthritis: Comment on the article by Stevens et al. Arthritis Rheum 1991;34:1508-1513.
14 Veihelmann A, Harris AG, Krombach F, Schuetze E, Refior HJ, Messmer K: In vivo assessment of synovial microcirculation and leukocyte-endothelial cell interaction in mouse antigen-induced arthritis. Microcirculation 1999;6:281-290.

15 Veihelmann A, Szczesny G, Nolte D, Krombach F, Refior HJ, Messmer K: A novel model for the study of synovial microcirculation in the mouse knee joint in vivo. Res Exp Med 1998;198:43-54.

16 Brackertz D, Mitchell GF, Mackay IR: Antigen-induced arthritis in mice. I. Induction of arthritis in various strains of mice. Arthritis Rheum 1977;20:841-850.

17 Haris AG, Hecht R, Peer F, Nolte D, Messmer $\mathrm{K}$ : An improved intravital microscopy system. Int J Microcirc Clin Exp 1997;17:322-327.

18 Zeintl H, Sack FU, Intaglietta M, Messmer K: Computer assisted leukocyte adhesion measurement in intravital microscopy. Int J Microcirc Clin Exp 1989;8:293-302.

19 Risau W: Review: Mechanisms of angiogenesis. Nature 1997;386:671-674.

20 Weidner N, Semple JP, Welch WR, Folkman J: Tumor angiogenesis and metastasis-correlation in invasive breast carcinoma. N Engl J Med 1991;324:1-8.

21 Colville-Nash P, Scott DL: Angiogenesis and rheumatoid arthritis: Pathogenic and therapeutic implications. Ann Rheum Dis 1992;51: 919-925.

22 Fitzgerald O, Soden M, Yanni G, Robinson R, Bresnihan B: Morphometric analysis of blood vessels in synovial membranes obtained from clinically affected and unaffected knee joints of patients with rheumatoid arthritis. Ann Rheum Dis 1991:50:792-796.

23 Koch AE, Harlow LA, Haines GK, Amento FP, Unemori EN, Wong WL, Pope RM, Ferrara N: Vascular endothelial growth factor. A cytokine modulating endothelial function in rheumatoid arthritis. J Immunol 1994;152:4149-4156.

24 Luttun A, Tjwa M, Wu Y, Angelillo A, Liao F, Nagy J, Hooper A, Priller J, De Klerck B, Compernolle V, Daci E, Bohlen P, Deverchin M, Herbert J, Fava R, Matthys P, Carmeliet G, Collen D, Dvorak H, Hicklin D, Carmeliet P: Revascularization of ischemic tissues by PIGF treatment and inhibition of tumor angiogenesis, arthritis and atherosclerosis by anti-Flt1. Nat Med 2002;8:831-840.
25 Paleolog EM, Young S, Stark AC, McCloskey RV, Feldmann M, Maini RN: Modulation of angiogenic vascular endothelial growth factor (VEGF) by TNF $\alpha$ and IL-1 in rheumatoid arthritis. Arthritis Rheum 1998;41:12581265.

26 Matsubara T, Saura R, Hirohata K, Ziff M: Inhibition of human endothelial cell proliferation in vitro and neovascularisation in vivo by $D$-penicillamine. J Clin Invest 1989;83:158167.

27 Hirata S, Matsubara T, Saura R, Tateishi H, Hirohota $\mathrm{K}$ : Inhibition of in vitro vascular endothelial cell proliferation and in vitro neovascularisation by low dose methotrexate. Arthritis Rheum 1989;32:1065-1073.

28 Levick JR: Microvascular architecture and exchange in synovial joints. Microcirculation 1995;2:217-233.

29 Harris AG, Steinbauer M, Leiderer R, Messmer K: Role of leukocyte plugging and edema in skeletal muscle ischemia-reperfusion injury. Am J Physiol 1997;372:989-996.

30 Jackson JR, Seed MP, Kircher CH, Willoughby DA, Winkler JD: The codependence of angiogenesis and chronic inflammation. FASEB $\mathrm{J}$ 1997;11:457-465.

31 Tak PP, Thurkow EW, Daha MR, Kluin PM, Smeets TJM, Meinders AE, Breedveld FC: Expression of adhesion molecules in early rheumatoid synovial tissue. Clin Immunol Immunopathol 1995; 77:236-242.

32 Koch AE, Halloran MM, Haskell CJ, Shah MR, Polverini PJ: Angiogenesis mediated by soluble forms of E-selectin and vascular adhesion molecule-1. Nature 1995;376:517-519.

33 van Netten JP, Cann SA, van der Westhuizen NG: Angiogenesis and tumor growth. N Engl J Med 1995;334:920-921.

34 Szczesny G, Veihelmann A, Nolte D, Messmer $\mathrm{K}$ : Changes in local blood and lymph microcirculation in response to direct mechanical trauma applied to leg: In vivo study in an animal model. J Trauma 2001;51:508-517. 